\title{
The Evaluation of Physician Counseling when Prescribing New Medications: An Observational, Survey Study
}

\author{
Latifa Al-Buainain ${ }^{1}$, Suha Malek ${ }^{2}$, Hamad Ammar ${ }^{1,2, ~ *, ~ S a w s a n ~ A b d u l l a ~ H a s a n ~}{ }^{1,2}$, \\ Asma Abu Baker Hasan ${ }^{2}$ \\ ${ }^{1}$ Department of Surgery, Bahrain Defense Force Hospital, Riffa, Bahrain \\ ${ }^{2}$ Royal College of Surgeons in Ireland- Medical University of Bahrain, Muharraq, Bahrain
}

Email address:

latifa_ra@yahoo.com(L.Al-Buainain),malek.suha@gmail.com (S. Malek), hamadammar@yahoo.com (H. Ammar), 14002281@rcsi.com (S. A. Hasan), 14002493@rcsi.com (A. A. B. Hasan)

${ }^{*}$ Corresponding author

To cite this article:

Latifa Al-Buainain, Suha Malek, Hamad Ammar, Sawsan Abdulla Hasan, Asma Abu Baker Hasan. The Evaluation of Physician Counseling when Prescribing New Medications: An Observational, Survey Study. American Journal of Internal Medicine. Vol. 8, No. 2, 2020 , pp. 57-61. doi: 10.11648/j.ajim.20200802.12

Received: February 2, 2020; Accepted: February 18, 2020; Published: March 3, 2020

\begin{abstract}
Patient education about medications being used highly improves the quality of proper use and compliance, to which the WHO has created guidelines of good prescribing. The main objective of this observational study is to assess the effectiveness of physician counseling and their compliance to the WHO guidelines to good prescribing when given the chance to prescribing new medications to patients coming for a follow up in various clinics in the Bahrain Defense Force Hospital in the form of a survey over a period of two weeks. 401 patient interviews were randomly chosen and included in the data analysis. 33 physicians were assigned in the survey, from which there were 7 cardiologists, 5 general practitioners, 3 diabetologists, 3 dermatologists, 2 endocrinologists, 5 pediatricians, 3 vascular surgeons, and 5 internists. The survey was developed based on the standards mentioned in the WHO guidelines. The main outcome was to observe and assess how efficient are physicians from various clinics in successfully prescribing new medications to patients through ten WHO standards. Data revealed that in general and for the most part the quality of instructions and information given to patients while prescribing new medications was relatively unsatisfactory in most clinics, although it was found that prescribing patterns differs from one physician to the other.
\end{abstract}

Keywords: Survey, Observational Study, WHO Guidelines, Good Prescribing, New Medications

\section{Introduction}

Patient education about medications being used highly improves the quality of proper use and compliance. "Medicines play a crucial role in the delivery of healthcare service across the globe. When medicines are unavailable, the morale of healthcare workers is dwindled, and public confidence in the health system is destroyed." [1] It is extremely important that this issue is addressed by physicians through proper instructions during outpatient clinic visits. It has been highly apparent and assumed that healthcare professionals and patients are starting to view the prescription of medicines to be an essential outcome of the visit; and therefore, the manner in which they are prescribed is definitely a reflection of the quality of healthcare in a hospital. It is the physician's responsibility to allocate a good amount of time during the visit to inform the patients about: a. drug name b. adverse effects c. drug purpose d. allergy possibility e. making sure there is an understanding by the patient. As one article clearly states that "nearly one-half of older adults take five or more medications, and as many as one in five of these prescriptions is potentially inappropriate." [8] In order to try to have a better impact on the quality of care given to the patients visiting clinics and increasing patient adherence to medications in Bahrain Defense Force hospital, we decided to conduct a survey across eight different clinics (cardiac, GP, diabetic, dermatology, endocrine, pediatrics, vascular, and internal 
medicine [Rheumatology + neurology + nephrology]) studying the effectiveness of drug prescribing by various physicians, with an that more emphasis by physicians should be allocated towards the education of medication prescribed to patients.

\section{Methods}

An observational study was conducted using a survey created in comparison with the WHO guidelines of good prescribing. The survey was applied by observing physician's method of educating patients in relation to prescribing. Data was collected across eight clinics (cardiac, GP, diabetic, dermatology, endocrine, pediatrics, vascular, and internal medicine [Rheumatology+neurology+nephrology]) in the Bahrain Defense Force hospital from physician-patient communication after being prescribed new medications. This was completed over a course of two weeks, in which 401 patient interviews were randomly chosen through simple randomization and included in the data analysis. 33 physicians were assigned in the survey, from which there were 7 cardiologists, 5 general practitioners, 3 diabetologists, 3 dermatologists, 2 endocrinologists, 5 pediatricians, 3 vascular surgeons, and 5 internists. The survey was developed based on the standards mentioned in the WHO guidelines which included: 1. Asking about current medications 2. Allergy 3. The name of the drug 4. The purpose of the drug 5 . The treatment duration 6 . The number of tablets 7. Intake timing or frequency 8. Drug adverse effect 9. Warning 10. Ensuring patient's understanding. The survey was filled by observing doctors' communication with the patients in prescribing new medications during the visit and explanation of the standards. Data analysis was completed through Microsoft Excel spreadsheet and the percentages generated by calculating how frequent the doctor explained the clarified points from the guidelines. A doubleblinded procedure has been attempted to prevent any biased audited results, and patients attending as a follow up were excluded as the study only included the prescribing of new medications as mentioned above.
Table 1. Medications prescribed in various outpatient clinics.

\begin{tabular}{lll}
\hline Outpatient Clinics & $\begin{array}{l}\text { Total Number of } \\
\text { medications/patients }\end{array}$ & $\begin{array}{l}\text { Total Number } \\
\text { of Physicians }\end{array}$ \\
\hline Cardiac & 48 & 7 \\
GP clinic & 54 & 5 \\
GP Diabetes Clinic & 51 & 3 \\
Dermal Clinics & 55 & 3 \\
Endocrine Clinics & 53 & 2 \\
Pediatrics Clinics & 50 & 5 \\
Vascular Clinics & 38 & 3 \\
Medicine (Rheumatology + & 52 & 5 \\
Neurology + Nephrology) & & \\
\hline
\end{tabular}

\section{Results}

After two weeks of observation 401 new medications were prescribed to same number of patients. These patients were indiscriminately chosen through simple randomization, and the patients includes both females and males, all ages, and various education levels from different socioeconomic backgrounds.

This variety in patient sample was especially important to obtain a proper understanding of how effective a physician's ability is to properly adhere by the WHO guidelines on good prescribing of new medications. As seen in the first table (table 1) it is foremost to first mention that the highest number of patients chosen in random for this study was from the dermatology clinic (55 patients), followed by (in decreasing order): GP clinic (54 patients), Endocrine clinic (53 patients), internal medicine clinic (52 patients), diabetic clinic (51 patients), pediatric clinic (50 patients), cardiac clinic (48 patients), and last the vascular surgery clinic (38 patients).

The table below (table 2) summarizes the data gathered from each clinic. It demonstrates the total number of newly prescribed medications, number of patients in each clinic as described above, as well as the number of patients who were given the information needed and percentages of compliance to the standards given by the WHO guidelines.

Table 2. Data breakdown in clinics.

\begin{tabular}{|c|c|c|c|c|c|c|c|c|}
\hline & $\begin{array}{l}\text { Cardiac } \\
\text { Clinics } \\
\end{array}$ & GP Clinics & $\begin{array}{l}\text { GP Diabetes } \\
\text { Clinics }\end{array}$ & $\begin{array}{l}\text { Dermal } \\
\text { Clinics }\end{array}$ & $\begin{array}{l}\text { Pediatrics } \\
\text { clinic }\end{array}$ & $\begin{array}{l}\text { Endocrine } \\
\text { Clinics } \\
\end{array}$ & $\begin{array}{l}\text { Vascular } \\
\text { Clinics } \\
\end{array}$ & $\begin{array}{l}\text { Medicine } \\
\text { Clinics }\end{array}$ \\
\hline Total number of patients & 48 & 54 & 51 & 55 & 50 & 53 & 38 & 52 \\
\hline current medication & $47(98 \%)$ & $33(61 \%)$ & $28(55 \%)$ & $15(27 \%)$ & $23(46 \%)$ & $51(96 \%)$ & $18(47 \%)$ & $48(92 \%)$ \\
\hline Allergy (drug) & $2(4 \%)$ & $17(31 \%)$ & $4(8 \%)$ & $0(0 \%)$ & $4(8 \%)$ & $0(0 \%)$ & $1(3 \%)$ & $2(4 \%)$ \\
\hline Name & $45(94 \%)$ & $45(83 \%)$ & $48(94 \%)$ & $50(91 \%)$ & $47(94 \%)$ & $53(100 \%)$ & $30(79 \%)$ & $43(83 \%)$ \\
\hline Purpose or justification & $31(65 \%)$ & $30(56 \%)$ & $34(67 \%)$ & $29(53 \%)$ & $19(38 \%)$ & $31(58 \%)$ & $21(55 \%)$ & $33(63 \%)$ \\
\hline Duration of intake & $25(52 \%)$ & $18(33 \%)$ & $24(47 \%)$ & $30(55 \%)$ & $14(28 \%)$ & $14(26 \%)$ & $11(29 \%)$ & $19(37 \%)$ \\
\hline No. tablets / sprays & $26(54 \%)$ & $36(67 \%)$ & $42(82 \%)$ & $39(71 \%)$ & $11(22 \%)$ & $33(62 \%)$ & $12(32 \%)$ & $35(67 \%)$ \\
\hline Frequency or timing of intake & $20(42 \%)$ & $34(63 \%)$ & $37(73 \%)$ & $33(60 \%)$ & $14(28 \%)$ & $24(45 \%)$ & $12(32 \%)$ & $38(73 \%)$ \\
\hline Adverse effects & $9(19 \%)$ & $7(13 \%)$ & $8(16 \%)$ & $3(5 \%)$ & $0(0 \%)$ & $2(4 \%)$ & $0(0 \%)$ & $2(4 \%)$ \\
\hline Warning (If needed) & $9(19 \%)$ & $11(20 \%)$ & $11(22 \%)$ & $8(15 \%)$ & $0(0 \%)$ & $6(11 \%)$ & $3(8 \%)$ & $6(12 \%)$ \\
\hline Everything clear / Q? & $7(15 \%)$ & $4(7 \%)$ & $24(47 \%)$ & $9(16 \%)$ & $2(4 \%)$ & $0(0 \%)$ & $2(5 \%)$ & $0(0 \%)$ \\
\hline
\end{tabular}

The cardiac clinic was noted to have the highest rate of asking about the current medications ( $98 \%$ of the time), followed by (in decreasing order): endocrine clinic ( $96 \%$ of the time), internal medicine ( $92 \%$ of the time), GP clinic ( $61 \%$ of the time), diabetic clinic ( $55 \%$ of the time), vascular surgery clinic ( $47 \%$ of the time), pediatric clinic ( $46 \%$ of the 
time), dermatology clinic ( $27 \%$ of the time).

On the other hand, compliance with regards to asking about any allergies was low all around but the highest in the GP clinics. During the prescription process, informing the patient about the medication name, the purpose of the drug, and the duration of intake was similar in percentage throughout all clinics except for the GP clinic where the intake of duration was a at a low of $33 \%$. Explaining to the patients the number of tablets and frequency was highest in the diabetic clinic followed by the GP clinic and lowest in the dermatology clinic. The last three standards of the guidelines which are the instructions given in relation to drug adverse effects, warning and making sure that everything is clear to the patient was altogether low compared to the other standards. "adverse drug reactions account for more morbidity and mortality than most chronic diseases, with death rates higher than many common cancers." [8]

Table 3. Compliance to guidelines.

\begin{tabular}{lll}
\hline & Total & Total in \% \\
\hline Total Number Of patients & 401 & \\
Current Medication & 263 & $66 \%$ \\
Allergy & 30 & $7 \%$ \\
Name & 361 & $90 \%$ \\
Purpose & 228 & $57 \%$ \\
Duration & 155 & $39 \%$ \\
No Tablets & 234 & $58 \%$ \\
Frequency & 212 & $53 \%$ \\
Adverse Effect & 31 & $8 \%$ \\
Warning & 54 & $13 \%$ \\
Everything Clear & 48 & $12 \%$ \\
\hline
\end{tabular}

The third table displays the total number of medications, and the overall percentages of compliance to the standards in the guidelines from all clinics. Compliance to informing the patient of the drug name was high by $90 \%$, instructions given in relation to the number of tablets needed to be takes was $58 \%$, questions related to current medications was $66 \%$, educating the patient about the drug purpose was $57 \%$, and about the frequency was $53 \%$. As for concerns about allergy was at a low of $7 \%$. Warning and ensuring that everything was clear to the patient was at $13 \%$ and $12 \%$.

\section{Discussion}

The appropriate use of medicines and good therapy is related to many factors. The WHO guideline standards of good prescribing are 10 and are as following: Standard 1: asking about current medications, standard 2: asking about allergies, standard 3: The name of the drug, standard 4: the purpose of the drug, standard 5: the treatment duration, standard 6: the number of tablets, standard 7: intake timing or frequency, standard 8: drug adverse effects, standard 9: warning and standard 10: ensuring patient's understanding.

According to the WHO $50 \%$ of patients' irregular medication intake are due to [2] one or more of the following: patient symptoms relieved before the end of the medication course, concerns about the drug's side effects, the drug takes a long time to achieve the desirable effects, multiple medications mainly in elderly patients leads to misunderstanding. However, all these factors are highly influenced on the education given to the patients by prescribing physicians, which plays an important role in enhancing compliance. In this audit, the physicians in the clinics were observed and noted whether they met the WHO criteria of good prescribing. This was especially important as these guidelines were established to increase patient compliance with the medications by fully understanding the drug prescribed to them.

The first standard is patient current medication history, which is always emphasized by doctors in order to avoid drug interactions that can either reduce or stop medication effects or cause undesirable affects. In addition, it helps physicians in planning the treatment to avoid interactions. [3] As a result, physicians try to always ensure to ask patients about current medications used especially in clinics following up chronic diseases. If the patients would have forgotten the drug name then it would easily be retrieved from the electronic system or try to remind the patient by either showing them a catalogue which contains medication boxes or pill shapes. In the dermatology clinic, the inquires about the patient current medications were relatively low as most of the drugs prescribed are topical and would either have no risk of drug interaction or a very low risk. However, if in rare times a patient needs to take an oral drug then the doctors do ask about other medications used.

The second standard is inquiries about history of allergies, and it was low in all clinics since the patient's history is stored in the electronic system and therefore, physicians depend on the information already updated on it.

During the prescription process, the third and fourth standards are mentioned together that is because informing the patient the exact name of the medication could be hard for the patient to remember especially if the patient is illiterate or has a low education. Therefore, physicians would mention the name of the drug along with the purpose of the drug to facilitate the patients understanding. For instance, cardiologists clarify the drug name and purpose by saying "this is a diuretic that will decrease the volume fluid in your body and reduced your blood pressure" or "this drug reduces your blood pressure." Likewise, another example would be when the dermatologist would say "this gel is to reduce the dark spots on your face."

The fifth, sixth and seventh standards (number of tablets, frequency and duration) were explained most of the time by physicians especially if the prescribed drug was an antibiotic. However, at times this was missed as physicians would assume that this would be explained to patients by the pharmacist which in most cases does not happen. Therefore, it is important to emphasize on the point that all physicians prescribing new medications must be given by the physicians as it has been proven by studies that instructions given by pharmacists can be erroneous leading to complications. [4]

The eighth and ninth standard of informing patients of adverse effects and warning was generally low in all clinics. 
This is due to the perception that mentioning adverse effects increases the incidence of a patient developing it and many patients are only concerned about these effects without being able to weigh the benefits versus the risk and this might cause reluctance in wanting to use the drug. As it was manifested in one of the studies, full explanation about medication, including information regarding the adverse effects can cause patient aversion from medication intake due to over rating of the drug risk. [5] However; it was noted that the doctor does warn the patient about the effect of the drug if it is related to the drug intake timing, or if the drug can cause sedation and should be taken at night.

The tenth and last standard of ensuring patients understanding was seen more often to be met in clinics that dealt with chronic diseases, as there are numerous drugs being prescribed and various instructions that needs to be followed. Of note, different clinics dealt with his standard in their own way. For example, in the diabetic clinic the physician reiterates the instructions to the patients until they ensure full patient understanding. In the cardiac clinic cardiologists would emphasize the importance of taking the medication (s) to the patient and the accompanying care giver as most of the demographic patient age was of old age.

This study was done to try to make a difference in prescribing medications and raise awareness to physicians about the importance of physician-patient communication and education to improve quality of life. Although, there were some limitations noted that may have influenced results. The main limitation was observer bias, as some physicians knew they were being audited and observed. Another limitation was that the data collection duration was short and therefore it would be more favorable to increase the duration.

\section{Conclusion}

The whole aim of this study was to answer the question of how eminent physicians are in prescribing new medications to patients in clinics, "demonstrating a convincing link between shared decision making and patient benefit is challenging." [7] Through this observational study, and although it was found that prescribing patterns differs from one physician to the other, however; the data collected revealed that in general and for the most part the quality of instructions and information given to patients while prescribing new medications in the Bahrain Defense Force Hospital was relatively unsatisfactory in most clinics and needs improvement. This is important in daily clinical practice as research shows that patient education and physician-patient communication has a significant impact on compliance to medications. Therefore, what is needed is to increase physician knowledge about the WHO guidelines of good prescribing and to monitor their ability to follow these guidelines from time to time. Another step to also start thinking about in proper prescribing is a new term called deprescribing as many has started to discuss this term it has been stated that "With too many patients taking too many unnecessary medications, deprescribing has become a required skill.” [9]

\section{References}

[1] Richard Ofori-Asenso. A closer look at the World Health Organization's prescribing indicators. Journal of Pharmacology and Pharmacotherapeutics [Internet] 2016 JanMar [cited 10 July 2019]; 7 (1): 51-54. Available from: https://www.ncbi.nlm.nih.gov/pmc/articles/PMC4831494/.

[2] De Vries TPGM, Henning RH, Hogerzeil HV, Fresle DA. Guide to good prescribing: a practical manual. Generva: World health organization, 1994. (WHO/DAP/94.11).

[3] Fitzgerald RJ. Medication errors: the importance of an accurate drug history. British journal of clinical pharmacology. 2009; 67 (6): 671-5.

[4] Pounds G, De Pablos-Ortega C. Patient- centered communication in British, Italian and Spanish 'Ask-theExpert' healthcare websites. Communication \&medicine. 2015; 12 (2-3): 225-41.

[5] Berry DC, Knapp P, Raynor DK. Provision of information about drug side-effects to patients. Lancet (London, England). 2002; 359 (9309): 853-4.

[6] N. Barber. What Constitutes good prescribing. BMJ [Internet] 1995 Apr. 8; 923-925. Available from: https://www.ncbi.nlm.nih.gov/pmc/articles/PMC2549298/.

[7] Weiss MC, Platt J, Riley R, Chewning B, Taylor G, Horrocks $\mathrm{S}$, Taylor A. Medication decision making and patient outcomes in GP, nurse and pharmacist prescriber consultations. Prim Health Care Res Dev. 2015 Sep16; 513527. Available from: https://www.cambridge.org/core/services/aop-cambridgecore/content/view/8302D507A16EB5814405724276E7EC79/ S146342361400053Xa.pdf/medication_decision_making_and patient outcomes in gp nurse and pharmacist prescriber consultations.pdf.

[8] Barbara Farrell, Dee Mangin. Deprescribing Is an Essential Part of Good Prescribing. Am Fam Physician. 2019 Jan 1 [Cited 17 February 2020]; 99 (1): 7-9. Available from: https://www.aafp.org/afp/2019/0101/p7.html?cmpid=b099f19 2-4ec0-4cde-ab60-

$3 \mathrm{a} 87 \mathrm{fbfa} 34 \mathrm{da} \& u$ tm campaign $=$ afp\&utm div=pub\&utm miss ion $=$ ce\&utm_prod $=$ afpj\&fbclid $=$ IwAR00OIE7QC_VKvtUAE zvatavCi5eUSMTL1P9P4m9iA0I3CLSmmWFH4üoljc.

[9] Scott Endsley. Deprescribing Unnecessary Medications: A Four Part Process. Fam Pract Manag. 2018 May-Jun [Cited 17 February 17, 2020]; 25 (3): 28-32. Available from: https://www.aafp.org/fpm/2018/0500/p28.html.

[10] Ranit Mishori. What Needs to Change to Make Deprescribing Doable. Fam Pract Manag. 2018 May-Jun; 25 (3): 5-6. Available

https://www.aafp.org/fpm/2018/0500/p5.html.

[11] Naik M, Nerurkar R, Phatak A, Panchal S, Paunikar A. A questionnaire-based study to assess rational prescribing practice among interns. Natl J Physiol Pharm Pharmacol 2015; 5: 323-327. Available from: https://www.njppp.com/fulltext/281430893143.pdf?1581923394. 
[12] Krishnaiah V, Ramaiah V, Ramakrishna R. Comparison of rational pharmacotherapy approach by medical students with and without Guide to Good prescribing guidelines. Natl J Physiol Pharm Pharmacol 2013; 3: 53-56. Available from: https://mail.google.com $/ \mathrm{mail} / \mathrm{u} / 0 /$.
[13] Simon Maxwell. Good Prescribing: better systems and prescribers needed. CMAJ 2010 Apr 6; 182 (6): 540-541. Available

from: 